\title{
Assembly of a Nanogold-Assisted Aptamer Sensor for Highly Sensitive Detection of Homocysteine
}

\author{
Shaoshuai Wang ${ }^{1}$, Yingzi Mi ${ }^{2}$, Guoyong Ren ${ }^{2}$, Yanjun Chen $^{2}$, Xuemei $W u^{2, *}$ \\ ${ }^{1}$ Department of Neurology, The First Hospital of Shanxi Medical University, Taiyuan, Shanxi \\ 030012,China. \\ ${ }^{2}$ Department of Neurology, General Hospital of Tisco, Taiyuan, Shanxi030008,China. \\ *E-mail: xuemeiwu0621@163.com
}

Received: 12 August 2021 / Accepted: 4 September 2021 / Published: 10 October 2021

\begin{abstract}
With more in-depth exploration on stroke risk factors in recent years, an increasing number of studies show that homocysteine (HCY) is a new risk factor of cerebral infarction. In this work, graphene was adopted for the modification of glassy carbon electrodes, and gold nanoparticles were modified onto the graphene surface with a simple and controlled electrodeposition method, followed by aptamer immobilization, to construct the homocysteine electrochemical sensor. Under optimum conditions, the analytical performance of the proposed aptamer sensor showed a positive response to different concentrations of HCY. The peak currents were proportional to HCY concentration. The linear regression equation can be found from $0.05-20.0 \mu \mathrm{M}$. The limit of detection can be calculated to be 5 $\mathrm{nM}$ based on $\mathrm{S} / \mathrm{N}=3$.
\end{abstract}

Keywords: Homocysteine; Aptamer; AuNPs; Graphene; Cerebral infarction

\section{FULL TEXT}

(C) 2021 The Authors. Published by ESG (www.electrochemsci.org). This article is an open access article distributed under the terms and conditions of the Creative Commons Attribution license (http://creativecommons.org/licenses/by/4.0/). 